\title{
EPISTEMOLOGIA MORAL COERENTISTA EM RAWLS 1
}

\author{
Denis Coitinho Silveira \\ Universidade Federal de Pelotas/CNPq
}

\begin{abstract}
My main aim in this paper is to analyze the problem of moral justification in John Rawls`s works such as A Theory of Justice (TJ, IX, § 89), Political Liberalism (PL III, § 2), Justice as Fairness: A Restatement (JF I, § 9), The Law of Peoples (LOP I, § 1), "Outline of a Decision Procedure for Ethics" (ODPE), "The Independence of Moral Theory" (IMT), "Justice as Fairness: Political not Metaphysical" (JFPnM). I wish to characterize the theory of justice as fairness as a coherentist system of justification, that relies with a holistic coherentist epistemology, a social contract theory that introduces a social ontology and a pragmatist strategy in the contractarian theory. In the scope of this work, I will analyze the core characteristics of the holistic coherentist epistemology presupposed and how its solve the problems of epistemic regress, dogmatism, dualism, asymmetry and circularity.
\end{abstract}

KEYWORDS: moral justification, moral epistemology, holistic coherentism.

RESUMO: Meu principal objetivo neste artigo é analisar o problema da justificação moral para John Rawls a partir dos textos A Theory of Justice (TJ, IX, § 87), Political Liberalism (PL III, § 2), Justice as Fairness: A Restatement (JF I, § 9), The Law of Peoples (LoP I, § 1), "Outline of a Decision Procedure for Ethics" (ODPE), "The Independence of Moral Theory" (IMT), "Justice as Fairness: Political not Metaphysical" (JFPnM). Minha intenção é a de caracterizar a teoria da justiça como equidade como um sistema coerentista de justificação que conta com uma epistemologia coerentista holística, uma teoria do contrato social que introduz uma ontologia social e uma estratégia pragmatista na teoria contratualista. No escopo deste trabalho, analisarei as características da epistemologia coerentista holística pressuposta e de como ela resolve os problemas de regresso epistêmico, dogmatismo, dualismo, assimetria e circularidade.

PALAVRAS-CHAVE: justificação moral, epistemologia moral, coerentismo holístico.

\footnotetext{
1 O presente trabalho foi realizado com apoio da CAPES - Coordenação de Aperfeiçoamento de Pessoal de Nível Superior e do CNPq - Conselho Nacional de Desenvolvimento Científico e Tecnológico - Brasil. Agradeço ao apoio recebido por Catherine Audard no desenvolvimento desta pesquisa.
} 


\section{Situando o Problema}

O problema central enfrentado pela teoria da justiça como equidade de John Rawls sempre foi o de procurar estabelecer a justificação da norma moral a partir de um afastamento em relação às estratégias fundacionalistas, como as do intuicionismo, perfeccionismo, idealismo transcendental, naturalismo e dedutivismo cartesiano, por exemplo (PL III, § 1-2: 90-101; TJ I, § 7-9: 34-53/30-46 rev.; IV, § 40: 251-257/221-227 rev.; IX, § 87: 577-578/506 rev.). O fio condutor de todas estas teorias morais é o estabelecimento de um sistema inferencial, em que um critério moral é inferido (ou de forma dedutiva ou de forma indutiva) de um fato moral, fato este que conta como fundamento último. O fundacionalismo em epistemologia moral é a tendência do estabelecimento da justificação da regra a partir de sua correspondência com um fato, isto é, a partir da identificação de sua verdade, tomando como correlatos os termos justificação e verdade. Por oportunizar um ponto último de ancoragem para a fundamentação dos princípios morais, o fundacionalismo pode evitar os problemas de regresso epistêmico e circularidade. Os seus principais problemas, além da referência metafísica a um fundamento último, dogmatismo, encontram-se na implicação dualista e na assimetria entre os termos, uma vez que se pode inferir o critério do fato, mas não se pode inferir o fato do critério $^{2}$.

\footnotetext{
2 O fundacionalismo é uma tese geral em epistemologia que defende que as crenças são justificadas a partir das relações lógicas existentes entre as crenças que necessitam de justificação e as crenças que não precisam de justificação em razão de serem autojustificadas ou autoevidentes. Esta tese pode ser entendida por contar com a relação entre: (i) crenças autojustificadas e (ii) crenças inferidas das crenças autojustificadas. No modelo clássico, a principal característica é a afirmação de que algumas crenças são justificadas não-inferencialmente, isto é, são autojustificadas, o que oportuniza uma justificação nãocondicional, infalível. A infalibilidade da crença, assim, é a tese central do fundacionalismo. O seu principal problema epistemológico é o do dogmatismo, uma vez que as crenças autojustificadas são 0 fundamento último que contam como um fato. Por exemplo, tanto o racionalismo como o naturalismo podem ser considerados dogmáticos em razão de contarem com premissas evidentes que servem de fundamento para o estabelecimento da norma. No primeiro caso, se presume que os primeiros princípios sejam verdadeiros e se usa um raciocínio dedutivo para se chegar aos princípios morais. No segundo caso, se parte de conceitos não-morais e se induz os princípios morais. Ver JAMIESON, 2000: 482. Ver, também, SOSA; KIM, 2005: 105-106; BONJOUR, 2010: 177-202; DANCY, 2010a: 53-58; DANCY, 2010b: 535-536; ALSTON, 2010: 382-385; AUDI, 1993: 96-116; SOSA, 19995: 73-75; AUDI, 2003: 193195; BRINK, 1989: 101-104. Para a assimetria e unidirecionalidade do fundacionalismo e simetria do coerentismo, ver DANCY, 2010a: 110.
} 
$\mathrm{O}$ afastamento em relação às estratégias fundacionalistas representa uma tentativa de estabelecimento de uma teoria moral não-metafísica, que procura uma referência de simetria entre os termos para a justificação, superando tanto o dogmatismo quanto o dualismo. Para tal, Rawls recorre a uma estratégia coerentista que busca encontrar a validade da regra a partir de sua coerência dentro de um sistema e isto pode ser entendido como uma epistemologia moral coerentista holística, uma vez que a justificação do critério moral não será dada por sua correspondência a algum fato, mas por sua coerência com um sistema coerente de crenças, pois a justificação independente da verdade deve implicar em uma relação com a concepção moral inteira e de como ela se harmoniza com os juízos ponderados (considered judgments) em equilíbrio reflexivo (reflective equilibrium), uma vez que a "justificação é uma questão de apoio mútuo de várias considerações, todas harmonizadas em conjunto em uma concepção coerente" ${ }^{3}$, que pode deixar de lado as questões de significado e definição para o desenvolvimento de uma teoria da justiça substantiva, o que resolve o problema do regresso epistêmico, uma vez que a crença moral será justificada por sua coerência com um sistema coerente de crenças e não apenas por sua coerência com outra crença, seguindo o modelo quineano de justificação (TJ IX, § 87: 579/507 rev.) $)^{4}$. No que segue, abordarei a questão da justificação

\footnotetext{
${ }^{3} \mathrm{TJ}$ IX, § 87: 579/507 rev.: "They are central elements and devices of theory, but justification rests upon the entire conception and how it fits in with and organizes our considered judgments in reflective equilibrium. As we have noted before, justification is a matter of the mutual support of many considerations, of everything fitting together into one coherent view".

${ }^{4}$ Rawls reconhece textualmente que este tipo de estratégia justificacional está em proximidade com a concepção de justificação utilizada por Quine em Word and Object (Capítulo 1: Language and Truth) e Ontological Relativity and other Essays (Ensaio 4: Existence and Quantification). Ver TJ IX, § 87: 579, n. 33/507, n. 34 rev. Esta concepção de justificação pode ser compreendida por uma epistemologia naturalizada e pela característica do holismo. É uma forma deflacionalista de compreender o papel da verdade para a justificação, tomando 0 contexto como condição necessária para o significado. Para Quine, o significado sentencial é indeterminado, sendo sua teoria do significado holística, uma vez que as declarações devem comparecer ao tribunal da experiência não individualmente, mas como um corpo coletivo. Isto implica em pensar que os significados das sentenças são interdependentes, sendo um significado de uma sentença dependente do significado de outras, e pode ser mudado a partir da mudança de significado de qualquer sentença. Assim, significado é algo próprio não das partes, mas da teoria inteira. Isto se contrapõe ao atomismo que defende que cada sentença tem seu próprio significado. No $\S 5$ de Word and Object (Evidence), Quine diz que as palavras podem ser aprendidas como partes das sentenças longas e que algumas palavras podem ser aprendidas como sentenças de uma palavra através definição ostensiva direta aos seus objetos. Em ambos os eventos, os significados das palavras apontam para seu uso em sentenças e são condicionadas pelo estímulo sensível. Diz que qualquer teoria realística da evidência deve ser inseparável da psicologia do estímulo e resposta aplicada às sentenças. Ver QUINE, 1960: 17. Isto é semelhante à posição rawlsiana que parte do
} 
moral como problema central da justiça como equidade (justice as fairness) e as características centrais da epistemologia coerentista holística pressuposta pela teoria moral rawlsiana, a saber, (i) superação da dicotomia fato/valor; (ii) revisibilidade das crenças; (iii) reciprocidade na direção regra-caso; (iv) concepção de verdade não correspondentista; (v) intersubjetividade; (vi) distinção entre todo e parte e, também, de como ela resolve os problemas de regresso epistêmico, dogmatismo, dualismo, assimetria e circularidade.

\section{O Problema da Justificação Moral}

O problema da justificação (justification) é visto por Rawls como relacionado com a necessidade do acordo (consenso), compreendido como uma escolha na posição original (original position) que requer um equilíbrio reflexivo amplo (wide reflective equilibrium), uma vez que os critérios que serão aceitos (construídos) devem ser coerentes com os juízos ponderados dos indivíduos e com a teoria moral escolhida:

No que se refere à objeção geral, a resposta é que a justificação é uma argumentação endereçada àqueles que discordam de nós, ou a nós mesmos quanto estamos indecisos. Isto presume uma divergência de concepções entre pessoas ou internamente a uma pessoa, e busca convencer os outros ou a nós mesmos da razoabilidade dos princípios sobre os quais nossas reivindicações e juízos estão fundados. Sendo designada para reconciliar a partir de razões, a justificação procede a partir do que todas as partes envolvidas na discussão sustentam em comum. Idealmente, para justificar uma concepção de justiça para alguém é necessário fornecer uma prova destes princípios a partir de premissas que ambos aceitam, estes princípios tendo, por sua vez, a consequência de serem coerentes com nossos juízos ponderados. Assim, a mera prova não é justificação. Uma prova simplesmente demonstra as relações lógicas entre proposições. Mas as provas tornam-se

pressuposto de que alguns princípios morais podem ser vistos como naturais e até mesmo óbvios, e que se teria grande dificuldade para considerá-los como verdades necessárias ou mesmo para explicar seu significado. Os princípios são contingentes no sentido em que são escolhidos na posição original à luz dos fatos gerais, sendo uma estipulação razoável (reasonable stipulations) e não uma verdade moral necessária, uma vez que não há a suposição de que os princípios sejam autoevidentes. Ver TJ IX, § 87: $578 / 506$ rev. 
justificação na medida em que os pontos de partida são mutuamente reconhecidos, ou as conclusões tão abrangentes e convincentes que nos persuadem da validade da concepção expressa por suas premissas (TJ IX, § 87: 580-581/508 rev. $)^{5}$.

A natureza da justificação se encontra na possibilidade do consenso para o estabelecimento dos princípios morais através dos procedimentos justificacionais da posição original e do equilíbrio reflexivo. A estratégia é estipular algumas condições formais e substanciais para a escolha dos princípios morais a partir da escolha da teoria moral mais coerente com os valores comuns dos agentes (teorias conhecidas pela tradição como utilitarismo, intuicionismo, perfeccionismo, kantismo, justiça como equidade como uma reformulação do contratualismo) e com a função de garantir um ordenamento social, uma vez que os princípios são aplicados na estrutura básica da sociedade (TJ IX, § 87: 581-582/509-510 rev.). As condições da escolha são dadas na posição original, com a estratégia de estipular restrições razoáveis suficientes que podem ser aceitas por todos, como ordenamento, finalidade, publicidade, por exemplo, e conectá-las com o propósito dos princípios morais e seu papel em estabelecer os laços comuns (TJ IX, § 87: 581-583/509-511 rev. $)^{6}$. Note-se que a estratégia central é tomar por hipótese que se escolherá os critérios morais a partir de sua coerência com os próprios valores ponderados que são assumidos, uma vez que é necessário o

5 TJ IX, § 87: 580-581/508 rev.: "In regard to the general objection the reply is that justification is argument addressed to those who disagree with us, or to ourselves when we are of two minds. It presumes a clash of views between persons or within one person, and seeks to convince others, or ourselves, of the reasonableness of the principles upon wich our claims and judgments are founded. Being designed to reconcile by reason, justification proceeds from what all parties to the discussion hold in common. Ideally, to justify a conception of justice to someone is to give him a proof of its principles from premises that we both accept, these principles having in turn consequences that match our considered judgments. Thus mere proof is not justification. A proof simply displays logical relations between propositions. But proofs become justification once the starting points are mutually recognized, or the conclusions so comprehensive and compelling as to persuade us of the soundness of the conception expressed by their premises". Ver, também, JF I, § 9.2: 27 e JFPnM: 394.

${ }^{6}$ Rawls ressalta que a posição original tem uma natureza hipotética e convida a responder a questão da razão em se agir moralmente. Sublinha que este procedimento é um olhar para um tipo de mundo social, isto é, ela pressupõe um mundo social bem-ordenando, reconstruindo seus valores. É uma situação de imparcialidade. E ver nosso lugar na sociedade desta perspectiva de imparcialidade é vê-lo sub specie aeternitatis. Este ponto de vista da eternidade não é além do mundo, nem um ponto de vista transcendente. É uma forma específica de pensar e sentir que pressupõe que pessoas racionais e razoáveis podem agir moralmente em sociedade. Quer dizer, este ponto de vista da eternidade é um ponto de vista social. Ver TJ IX, § 87: 587/514 rev. 
reconhecimento mútuo para a justificação. Dado que justificação é (i) uma reconciliação a partir de razões, (ii) deve se tomar os valores comuns dos envolvidos como ponto de partida e (iii) validar estes valores pelo consenso, acordo e, assim, (iv) os princípios escolhidos devem ser coerentes com os juízos ponderados dos envolvidos, (v) uma vez que a justificação é dada não por prova, mas por mútuo reconhecimento. Com isto, se pode estipular que Rawls está usando de forma interconectada uma epistemologia coerentista holística (ECH), com o uso do procedimento do equilíbrio reflexivo e uma teoria do contrato social (TCS), com o uso do mecanismo da posição original, que introduz uma ontologia social com o construtivismo político. A ideia central da justiça como equidade é de que a sociedade deve ser um sistema equitativo de cooperação social ao longo do tempo e isto implica nas ideias de pessoas como livres e iguais e de sociedade bem-ordenada. São estes valores morais de pessoa e sociedade que são reconstruídos na teoria (TJ I, § 3: 11-17/10-15 rev.; JF I, § 2-3: 5-9; § 7: 18-24; PL I, § 3: 15-22; § 5-6: 29-40). Este ponto de vista social oportuniza um início não-metafísico para a teoria, uma vez que não são valores apriorísticos que seriam intuídos por um indivíduo. Esta ontologia social é o input não-metafísico da justiça como equidade que é coerente com a epistemologia holística em razão deste ponto de vista social estar em coerência com os juízos ponderados dos cidadãos em um sistema democrático constitucional ${ }^{7}$. Note-se que estes dois procedimentos estão integrados e possuem uma forte característica internalista em razão de sua dependência à estrutura mental dos agentes que devem escolher na posição original e em equilíbrio reflexivo amplo ${ }^{8}$.

\footnotetext{
7 Sobre a ontologia social, ver AUDARD, 2007: 56-61; PETTIT, 2005: 167-170; FREEMAN, 2007b: 209210.

${ }^{8}$ No internalismo, a justificação epistêmica depende dos elementos que são internos aos estados mentais conscientes dos agentes de uma forma em que eles estejam acessíveis em sua reflexão. É uma perspectiva de justificação em primeira pessoa. $O$ internalismo afirma que a justificação de uma crença $p$ por um sujeito $S$ se dá em termos de $S$ possuir razões para considerar $p$ verdadeiro. Em termos de filosofia moral, a crença moral $p$ é justificada pela motivação $m$ do sujeito $S$. No externalismo, a justificação epistêmica deriva de fatores externos ao dos estados mentais dos agentes, de uma forma a não levar em conta este escopo da consciência. É uma justificação em terceira pessoa. O externalismo afirma que a justificação de uma crença $p$ por um sujeito $S$ pode se dar em termos de $\mathbf{S}$ considerar $p$ confiável ou legítimo, por exemplo. Em termos morais, a crença moral $p$ pode ser afirmada independentemente da motivação moral $m$ do agente $S$. Também, se pode falar de razões internas e externas para a justificação da crença moral e a consequente ação. Ver BONJOUR, 2008: 5-41; BONJOUR, 2010: 40-41; BRINK, 1989: 37-43; SOSA, 1995: 193-198; SMITH, 1994: 60-62; AUDI, 2003: 328-242; ALSTON, 2005: 51-53; WILLIAMS, 2008: 292-298.
} 
O problema da estabilidade é acrescentado posteriormente na explicação de justificação, uma vez que este acordo deve garantir uma estabilidade social, gerando o seu próprio suporte moral, implicando no uso de uma estratégia externalista:

Desde que justificação é endereçada aos outros, isto procede do que é ou do que pode ser sustentado em comum; e então iniciamos de ideias fundamentais compartilhadas implícitas na cultura política pública com a esperança de desenvolver a partir delas uma concepção política que possa obter um acordo livre e racional, sendo este acordo estável em virtude dele obter o apoio de um consenso sobreposto de doutrinas abrangentes razoáveis ( $P L$ III, § 2.2: 100-101) ${ }^{9}$.

Veja-se que não há modificação da compreensão de justificação, dada a presença de todos os cinco itens anteriormente referidos. A diferença é que o item (iii) é visto como um consenso sobreposto (overlapping consensus) sobre doutrinas abrangentes razoáveis que tem o papel de garantir a estabilidade social e legitimidade política de uma forma coerente com o fato do pluralismo razoável (fact of reasonable pluralism). Ele possibilita uma unidade social através de um minimum moral que é mutuamente reconhecido por todos os envolvidos. Não há uma modificação na estrutura da justificação, apenas uma pequena correção através do acréscimo de uma estratégia pragmatista (EP), que adiciona um importante elemento externalista, constituindo-se como o output da teoria, o que possibilita evitar o problema da circularidade ${ }^{10}$. Assim, a TCS pode ser vista como uma teoria do contrato social pragmatista (TCSP).

\footnotetext{
${ }^{9}$ PL III, § 2.2: 100-101: "Since justification is addressed to others, it proceeds from what is, or can be, held in common; and so we begin from shared fundamental ideas implicit in the public political culture in hope of developing from them a political conception that can gain free and reasoned agreement in judgment, this agreement being stable in virtue of its gaining the support of an overlapping consensus of reasonable comprehensive doctrines". Ver, também, LoPI, § 1.3: 19.

10 Rawls adiciona uma EP em sua TCS para poder dar conta do problema da estabilidade de forma coerente com o fato do pluralismo razoável. Para ele, a forma com que foi tratado o problema da estabilidade na parte III de $T J$, com 0 argumento da congruência entre justo e bem, não foi suficientemente adequado, uma vez que a concepção de sociedade bem-ordenada não resultou realística, pois exigia uma correspondência abrangente entre as concepções de bem dos indivíduos com o critério do justo. Dado o pluralismo moral, é melhor pensar os princípios de justiça como um consenso sobreposto entre doutrinas abrangentes razoáveis que garante a estabilidade pelas retas razões e, assim, assegura a legitimidade. Ver PL: xvi-xviii. Importante notar que houve apenas um acréscimo na
} 
Isto parece apontar para o uso de um sistema coerentista de justificação em filosofia moral que possui as características de holismo, construtivismo contratualista e pragmatismo, integrando o problema da justificação da regra moral com o problema da estabilidade social e legitimidade política. Dessa forma, a teoria rawlsiana seria composta de (i) uma $\mathrm{ECH}$, com o uso do procedimento do equilíbrio reflexivo amplo, (ii) uma TCS que introduz uma ontologia moral social, com o uso do procedimento da posição original, (iii) uma EP na TCS que a modifica para TCSP, com o uso do procedimento do consenso sobreposto para a garantia da estabilidade-legitimidade, que é o mesmo que um equilíbrio reflexivo completo (full). Este sistema integra o problema da justificação com a questão da legitimação, tomando como complementares elementos internalistas e externalistas, em razão de seus procedimentos justificacionais estarem em harmonia e não em tensão ${ }^{11}$.

\section{Coerentismo Holístico}

Robert Audi aponta que a ideia central do coerentismo como uma tese geral em epistemologia é que uma crença é justificada por sua coerência com outras crenças que são asseguradas. Este coerentismo pode ser linear ou holístico. Na forma linear, a unidade da coerência pode ser tão ampla como a dada por um conjunto inteiro de crenças, embora algumas crenças possam ser mais significativas em produzir coerência que outras em razão da diferença de graus de sua proximidade com o tema da crença em questão. Assim, uma crença é justificada por outra crença dentro do sistema, quer dizer, uma crença p é justificada a partir de uma linha inferencial que busca por premissas para p e, assim, sucessivamente. Nesta concepção circular, não

\footnotetext{
TCS, que passou a contar com o procedimento do consenso sobreposto, não abandonando os procedimentos da posição original e equilíbrio reflexivo e que a ECH permaneceu a mesma.

${ }^{11}$ Scanlon aponta para uma tensão entre os procedimentos justificacionais usados por Rawls, uma vez que 0 equilíbrio reflexivo seria um método intuitivo e indutivo e a posição original seria mais teórica e dedutiva, sendo a razão pública mais restritiva que o equilíbrio reflexivo por fazer uso apenas de valores políticos para a justificação. Mesmo respondendo às objeções a respeito do possível conservadorismo e relativismo, Scanlon ressalta a tensão entre o descritivismo do equilíbrio reflexivo e razão pública com 0 prescritivismo da posição original. Ver SCANLON, 2003:139-167. Ver, também, WEBER, 2010: 91-101 e HEDRICK, 2010: 38 e 82. Creio que a ideia de complementaridade entre justificação e legitimação que integra elementos internalistas e externalistas para a justificação aponta para uma coerência entre os procedimentos e não tensão. A justiça como equidade pode ser vista como um sistema coerentista de justificação em que todos os seus elementos devem estar em harmonia.
} 
importa quão amplo seja o círculo ou a riqueza de suas partes constituintes, existindo uma linha de crenças em uma cadeia circular. Por sua vez, o coerentismo holístico defende que a crença justificada se harmoniza com um número substancial de outras crenças, mas não necessariamente com todas as crenças. Algumas crenças, como as que expressam princípios básicos do pensamento, podem ser justificadas apenas pela coerência com um grupo grande e diverso de crenças relacionadas. Dessa forma, a crença é justificada pela sua harmonia com o sistema, isto é, sua justificação se dá pelo papel que ela possui na validação do sistema. Esta justificação é indireta e nãoinferencial, em razão da crença se constituir em conhecimento não apenas por receber apoio de outras crenças, mas por não ser inferencialmente justificada. O estatuto epistêmico da crença é alcançado por sua coerência com um sistema de crenças que possui coerência, dependendo do suporte da estrutura integral das crenças à qual pertence (AUDI, 1993: 137-140) ${ }^{12}$.

A epistemologia moral coerentista holística assegura que uma crença moral é justificada na medida em que o conjunto de crenças do qual ela faz parte é coerente. Assim, cada crença moral é avaliada pelo papel que ela desempenha no conjunto coerente das crenças, evitando o problema do regresso epistêmico. Se a coerência do conjunto for fortalecida pela exclusão de uma crença ou mesmo pela substituição de uma crença oposta, a crença em questão não é justificada. Se o conjunto é mais coerente com a presença de uma crença preferencialmente que a qualquer outra crença alternativa, então, esta crença é justificada. Nesta forma de conceber a justificação de maneira coerentista holística não há a presença de pontos fixos dos quais outras crenças seriam inferidas. Cada crença é avaliada pela consideração do efeito de sua presença no sistema coerente, sendo testada por sua efetividade no sistema. Isto parece apontar para a presença de uma ontologia genérica pressuposta pelo sistema, uma vez que existe uma família de propriedades qualitativas (relacionais) que fazem de algo um constituinte de tal sistema,

\footnotetext{
12 Audi explica da seguinte maneira este coerentismo holístico: a justificação não é inferencial, enfatizando 0 apoio mútuo entre as crenças no interior de um sistema, levando em consideração os sistemas de crenças. Assim, (i) cada crença é justificada em razão de sua coerência com uma ou algumas crenças e (ii) as crenças permaneceriam justificadas mesmo se algumas das crenças não estiverem justificadas. Ver AUDI, 1988: 419-420. Ver, também, JAMIESON, 2000: 484; HUEMER, 2010: 25; SAYRE-MCCORD, 1996: 124-136; SOSA, 1995: 112-126; DANCY: 2010a: 116; BONJOUR, 1985; LEHRER, 2010: 278-281; BRINK: 1989: 103.
} 
sendo as partes deste sistema dependentes entre $\mathrm{si}^{13}$. Assim, a justificação da crença moral não é uma questão de correspondência a um fato moral ou uma dedução de premissas autoevidentes, mas é uma questão de apoio mútuo entre juízos e princípios morais no interior de um sistema coerente de crenças, isto é, no interior de uma teoria moral. Dessa forma, este modelo holístico de coerentismo parece contar com as seguintes características: superação da dicotomia fato/valor, revisibilidade das crenças, reciprocidade na direção regra-caso, concepção de verdade não correspondentista, intersubjetividade e distinção entre todo e parte ${ }^{14}$.

A justiça como equidade parece seguir este modelo coerentista holístico, dado que a justificação da crença é uma questão de apoio mútuo entre princípios e juízos ponderados harmonizados em um sistema coerente e não uma questão de correspondência a um fato ou uma dedução de premissas autoevidentes (TJ I, § 4: 21/19 rev.). Para Rawls, a filosofia moral é uma investigação sobre a conexão entre a estrutura das concepções morais e a sensibilidade moral humana (IMT: 287). Supera a dicotomia entre fato e valor, pois procura aplicar a ideia de tolerância à filosofia, tratando o problema da justificação como uma prática. Esta teoria pode evitar determinadas afirmações a respeito da verdade universal ou sobre a natureza e identidade das pessoas, partindo do pressuposto de que, em uma democracia constitucional, a concepção política de justiça seria, tanto quanto possível, independente de doutrinas abrangentes controversas. Assim, esta concepção pública de justiça é política e não metafísica, pois é uma concepção moral aplicada à estrutura básica de uma sociedade democrática, o que possibilita lidar com o problema do pluralismo moral razoável. Veja-se que o problema da justificação de uma concepção de justiça é visto em sua tarefa social prática e não apenas como um problema epistemológico ou

${ }^{13}$ Esfeld define um sistema holístico se e apenas se as partes que formam este sistema possuírem algumas das propriedades que são características comuns às partes do sistema. Diz que isto está conectado com uma ontologia genérica, pois as partes de um sistema holístico possuem uma interdependência, isto é, as partes possuem uma dependência mútua. Ver ESFELD, 1998: 367-375. Ver, também, DANCY, 2010a: 117; BRINK, 1989: 103-104; SOSA, 1995: 112-113; ROBINSON, 2006: 331-360.

${ }^{14}$ Bonjour salienta que a tese central do coerentismo é (i) da não existência de crenças fundacionais ou básicas e (ii) que a base para a justificação se funda no fato de que as crenças se harmonizam em conjunto e apóiam-se mutuamente, formando um sistema coerente de crenças com as seguintes características: a justificação é não-linear (holismo), deve ter consistência e estar fundada na observação, não possuindo uma meta-crença. Ver BONJOUR, 2008: 42-53. Com isto, temos que o valor não poderá ser visto como distinto dos fatos, uma vez que não há nenhum pressuposto dualista e dogmático, sendo a justificação da regra intersubjetiva, recíproca e revisável. 
metafísico. Dessa forma, o problema moral não é exclusivamente um problema metaético (JFPnM: 388-389). No artigo IMT, Rawls também defende a independência da filosofia moral em relação à epistemologia, uma vez que ela deve colocar entre parênteses o problema da verdade moral e da existência de fatos morais e investigar sobre as concepções morais substantivas dos indivíduos. Esta independência é em relação a uma epistemologia e ontologia tradicionais e revela uma tentativa de estipular a regra moral a partir de sua coerência com o próprio caso, interconectando os fatos e os valores para a justificação ${ }^{15}$.

Esta justiça procedimental pura toma como ponto de partida os valores morais-políticos de uma tradição política, de um regime constitucional democrático. Esta concepção pode ser apoiada por um consenso sobreposto sobre doutrinas abrangentes razoáveis, o que possibilita a estabilidade. Procura partir de convicções morais ponderadas compartilhadas em uma democracia constitucional e, então, busca organizar as ideias básicas e os princípios explícitos nestas convicções em direção a uma concepção coerente de justiça. Estes valores são tomados como pontos fixos provisórios, o que já demonstra a característica de revisibilidade das crenças. A justiça como equidade é esta concepção política de justiça que trata de forma coerentista e falibilista os seguintes elementos:

(i) convicções morais ponderadas compartilhadas, como, por exemplo, de rejeição à escravidão e tolerância religiosa, tomados pontos fixos provisórios;

(ii) princípios básicos que estão implícitos nestes juízos morais, como, por exemplo, princípios da igual liberdade, da igualdade equitativa de oportunidade e da diferença;

15 Ver IMT: 286-288. Ao final do artigo, Rawls reafirma a relação metodológica de prioridade entre a filosofia moral e as outras partes da filosofia, como a epistemologia, teoria do significado e filosofia da mente. Observa que a parte central da filosofia moral que é mais relevante é a teoria moral, consistindo no estudo comparativo de concepções morais, estudo este que é, em grande medida, independente. Assim, a exposição do método do equilíbrio reflexivo sugere que a questão sobre a existência de verdades morais objetivas parece depender de um tipo de acordo que seria obtido entre pessoas racionais que tenham alcançado um equilíbrio reflexivo amplo. Isto aponta para a dependência da epistemologia moral em relação à teoria moral. Não é uma abstinência epistêmica, apenas abstinência em relação a uma epistemologia tradicional, correspondentista. Ver IMT: 301-302. Para a crítica de epistemic abstinence, ver RAZ, 1990: 9-20. 
(iii) teoria da justiça que assume que a coerência entre crenças e princípios é a melhor alternativa para uma sociedade democrática (JFPnM: $393)^{16}$.

Já que justificação será um tipo de consenso, a ideia central é procurar uma base para o acordo público, e esta base é oportunizada pelos juízos ponderados em todos os níveis de generalidade; assim, a teoria articula as ideias intuitivas familiares e princípios que possam ser reconhecidos por todos (JFPnM: 393). A proposta é procurar encontrar um conjunto de princípios que sejam coerentes com os juízos ponderados e convicções gerais das pessoas em equilíbrio reflexivo, o que aponta para uma reciprocidade na direção regra/caso (pluridirecionalidade). Estes princípios devem representar as concepções morais dos indivíduos e sua sensibilidade moral. Como podem ser observadas várias crenças morais divergentes, isto é, um desacordo moral, o teórico moral deve ser um observador e deve proceder estudando as principais concepções morais fundadas na tradição da filosofia moral, incluindo as discussões de questões morais e sociais particulares. Aqui temos o procedimento do equilíbrio reflexivo amplo (wide), de forma que os princípios devem descrever as crenças morais ponderadas, por um lado, e estar em coerência com uma dada concepção moral, isto é, com uma teoria sobre o que é correto e errado objetivamente (IMT: 288). Veja-se que Rawls

\footnotetext{
${ }^{16}$ Isto mostra que a justiça como equidade concebe a justificação como um equilíbrio reflexivo amplo. Daniels explica que o método do equilíbrio reflexivo amplo (wide) é uma tentativa de produzir coerência em um conjunto triplo de crenças ordenadas asseguradas por uma pessoa particular, a saber, (i) um conjunto de juízos morais ponderados, (ii) um conjunto de princípios morais e (iii) um conjunto de teorias de fundo relevantes (background theories), sendo distinto do equilíbrio reflexivo estreito (narrow), que só leva em consideração a coerência entre (i) e (ii). Ver DANILES, 1979: 258-260; 1996: 1-3 e FREEMAN, 2007a: 29-42. Em ODPE, o método do equilíbrio reflexivo é o estreito (narrow). A ideia central era mostrar os princípios implícitos nos juízos ponderados (considered judgments) de juízes competentes (competent judges) a partir do seguinte método: (i) seleciona-se uma classe de juízos morais (a partir da moralidade de senso comum) e (ii) identifica-se se eles são coerentes com princípios razoáveis e justificáveis; se existe esta coerência, então, (iii) estes juízos morais são juízos ponderados (refletidos) e servem de critério justificacional para os princípios. A objetividade dos juízos morais ponderados depende de um procedimento de decisão razoável, quer dizer, a objetividade depende da razoabilidade que será alcançada pelos princípios. Assim passa-se a contar com princípios razoáveis e justificáveis para arbitrar o discenso moral. Os princípios são razoáveis, pois resultam de um mecanismo heurístico que deve expressar a razoabilidade. Os princípios que passam no teste de razoabilidade são aqueles que podem ser aceitos por homens razoáveis a partir de uma coerência com suas próprias intuições morais. Ver ODPE: 1-11. Esta é a mesma concepção de equilíbrio reflexivo que foi apresentada por Rawls em sua tese de doutorado de 1950 e sintetizada em ODPE. Ver A Study in the Grounds of Ethical Knowledge (SGEK), p. 269-270; 282-318.
} 
parece propor o procedimento do equilíbrio reflexivo amplo para solucionar o problema de uma fundamentação metafísica para os princípios de justiça através de uma estratégia coerentista holística, de uma forma em que os princípios devem descrever o senso moral ponderado dos indivíduos e servir de critério normativo para os juízos morais divergentes, uma vez que são construídos na teoria normativa e escolhidos por sua função prática de garantia da estabilidade-legitimidade. Este procedimento resolve o problema de como escolher entre sistemas coerentes alternativos, uma vez que a teoria da justiça como equidade estipula que a coerência entre juízos e princípios morais é a melhor alternativa para uma sociedade democrática, marcada pelo pluralismo moral, sendo superior ao utilitarismo, perfeccionismo e intuicionismo em razão de possibilitar a estabilidade-legitimidade, isto é, em razão de sua maior consistência. Para responder às críticas de conservadorismo do método do equilíbrio reflexivo, de maneira que a regra seria apenas a descrição de crenças e, assim, qualquer crença atual poderia ser justificada sem uma referência normativa, Rawls ressalta três aspectos: (i) os juízos morais ponderados são tomados como pontos fixos provisórios que podem ser revistos a partir dos princípios que são sustentados por uma teoria moral; não possuem o estatuto algumas vezes atribuído aos juízos da percepção e teorias do conhecimento; (ii) o equilíbrio reflexivo requer apenas que o agente faça as revisões com conviçcão e confiança e continue a afirmar os princípios, aceitando suas consequências na prática; (iii) o equilíbrio reflexivo amplo satisfaz certas condições de racionalidade, uma vez que os princípios são escolhidos com a consideração de concepções morais plausíveis e com a escolha da concepção moral mais razoável. Assim, os juízos morais ponderados não são tomados como fatos morais, pois eles (i) são revisáveis, (ii) não são autojustificados, (iii) possuem credibilidade (a partir de uma dada tradição), (iv) precisam ser testados (pelos princípios e com a teoria para a estabilidade $)^{17}$.

Dada a pluralidade moral, como escolher uma concepção mais razoável? A partir da rejeição a um modelo axiomático geométrico, se adota o procedimento do consenso mútuo (acordo), compreendendo os princípios como suficientes para possibilitar uma base construtiva de acomodação

\footnotetext{
17 Ver IMT: 289 e DANIELS, 1979: 256- 282. Ver as críticas de conservadorismo, relativismo e intuicionismo em WEBER, 2010: 101-110; RAZ, 1990: 4-15; DePAUL, 1987: 479-480; BRANDT, 1979: Ch. 1; LYONS, 1975: 145-149; HARE, 1975: 82-85; FEINBERG, 1975: 108-124; SINGER, 1974: 494; BARRY: 1973: 10-18.
} 
mútua: "É natural supor que a condição necessária para as verdades morais objetivas é que exista um acordo suficiente entre as concepções morais afirmadas em equilíbrio reflexivo amplo, um estado alcançado quando as convicções morais das pessoas satisfazem certas condições de racionalidade" (IMT: 290) ${ }^{18}$. Rawls diz que uma concepção política de justiça deve possibilitar uma forma razoável de moldar em uma concepção coerente a base profunda do acordo inserida na cultura pública de um regime constitucional de maneira aceitável para as mais firmes convicções ponderadas defendidas. Dessa forma, esta concepção possibilita um ponto de vista publicamente reconhecido, que é a base para a justificação do critério. Portanto, sendo a justificação dirigida aos outros que discordam de nós, ela deve proceder de um consenso, isto é, de premissas que possam ser publicamente reconhecidas como aceitáveis. Assim, justificação é reconhecimento (público) e não descoberta ${ }^{19}$. Aqui se percebe o uso de uma concepção de verdade não correspondentista, uma vez que o verdadeiro terá o significado de aceitável, sendo aquilo que é publicamente reconhecido como aceitável para nós com o propósito de estabelecer um acordo funcional sobre questões fundamentais de justiça política (JFPnM: 394) ${ }^{20}$.

Rawls quer seguir o modelo de Sidgwick, em Methods of Ethics, que procurou fazer uma exposição dos principais métodos em filosofia moral para só depois escolher o melhor método, ao dizer que a tarefa da teoria moral é fazer a exposição dos modelos alternativos que servirão de base para a escolha por consenso. Além do intuicionismo e utilitarismo e com a exclusão do egoísmo que para Rawls não é um método da ética, ele adiciona a necessidade de exposição do perfeccionismo e da ética kantiana para se proceder a avaliação (IMT: 290-291). Veja-se que este estudo é independente de outras partes da filosofia, como o da existência ou não da verdade moral. Assim, há uma prioridade da teoria moral e filosofia moral sobre a epistemologia e ontologia, isto é, há uma ordem de prioridade entre o

\footnotetext{
18 IMT: 290: "It is natural to suppose that a necessary condition for objective moral truths is that there be a sufficient agreement between the moral conceptions affirmed in wide reflective equilibrium, a state reached when people's moral convictions satisfy certain conditions of rationality".

19 Ver FREEMAN, 2007b: 216-224; LEHNING, 2009: 167-185; POGGE, 2007: 100-101; AUDARD, 2007: 205-206.

20 JFPnM: 394: "Rather, justification is addressed to others who disagree with us, and therefore it must always proceed from some consensus, that is, from premises that we and other publicly recognize as true; or better, publicly recognize as acceptable to us for the purpose of establishing a working agreement on the fundamental questions of political justice".
} 
trabalho de exposição das teorias morais conhecidas pela tradição e do método para a escolha da teoria e princípios que servirão de critérios para os juízos e o trabalho da epistemologia sobre a justificação da norma pelo critério de verdade. Isto parece conduzir para a adoção de uma epistemologia moral coerentista holística, uma vez que a justificação da crença não se dará por sua verdade, mas por sua harmonia com as outras partes do sistema coerente, isto é, com os princípios e com a teoria moral que têm a função de possibilitar a unidade social e estabilidade, revelando uma importante característica de justificação intersubjetiva. Por exemplo, as crenças de que "a escravidão é injusta" e de que "a tolerância religiosa é boa” são justificadas por sua coerência com os princípios de justiça, princípios estes que asseguram os valores de liberdade e igualdade, valores que são coerentes com os critérios de razoabilidade e cooperação que são estipulados na teoria, que, por sua vez, são coerentes com os valores daquelas crenças e, assim, aquelas crença são tomadas como ponderadas. A isto, Rawls chama de equilíbrio reflexivo amplo, uma vez que os juízos ponderados estão em coerência com os princípios de justiça e com a justiça como equidade de forma simétrica. Estes valores identificados na teoria são tomados como pontos fixos provisórios e não como pontos fixos (TJ I, § 4: 20/18 rev.; PL I, § 1.3: 8 e III, $\S$ 7.4: 124). Assim, a crença de que "a tolerância religiosa é boa" não é inferida do princípio da igual liberdade, que por sua vez seria inferido do valor de razoabilidade da teoria. Os valores são selecionados em razão da função prática de garantia de estabilidade e legitimidade. A crença é justificada pelo papel que ela desempenha dentro do sistema e por sua eficácia dentro do sistema em sua finalidade de alcançar a melhor forma de convivência social. Esta justificação não se dá de forma solipsista, mas pressupõe uma maneira de conceber o conhecimento como um fenômeno social $^{21}$.

\footnotetext{
${ }^{21}$ Importante lembrar que qualquer parte do sistema coerente pode ser revisado e substituído, o que aponta para a característica do falibilismo. O falibilismo não é um defeito, mas uma característica fundamental de uma epistemologia coerentista que estabelece uma revisão continuada na busca por mais coerência. Esta compreensão de justificação, então, supera o dualismo e o solipsismo. Ver WEBER, 2010: 69; GRAHAM, 2007: 38-41; FREEMAN, 2007a: 31. Esta característica de intersubjetividade também pode ser identificada no método de adjudicação, uma vez que a justiça como equidade pretende arbitrar (to adjudicate) as duas tradições conflitantes de liberdade e igualdade (i) propondo princípios de justiça para a estrutura básica da sociedade que harmonizam liberdade e igualdade, (ii) especificando um ponto de vista social para explicar a razão dos princípios serem os mais adequados. Ver JFPnM: 392.
} 
Nesta concepção de ECH, a justificação é um problema prático e não epistemológico ou metafísico, não sendo a justiça como equidade uma teoria verdadeira, mas que pode servir como base do acordo político entre cidadãos vistos como pessoas livres e iguais. Ao defender uma ordem de prioridade entre a filosofia moral e a teoria do significado, Rawls chama a atenção que uma definição mais adequada não é uma questão de significado, mas de como a teoria inteira se harmoniza em conjunto, isto é, de forma coerente ${ }^{22}$. Este é um tipo de acordo fundado em valores políticos e atitudes sociais que podem ser coerentes com as concepções de bem dos indivíduos e associações, procurando evitar as disputas de questões filosóficas e religiosas, não por serem questões irrelevantes, mas pela compreensão de que estes problemas não podem ser resolvidos pelo critério moral-político de justiça. Este tipo de acordo faz uso da ideia de tolerância, pois, dado o pluralismo moral razoável, a justificação é alcançada pelo reconhecimento dos envolvidos e não apelando para a verdade de uma ordem moral independente. Se a filosofia é tomada como a busca da verdade de uma ordem independente de valores, então ela não pode possibilitar uma base compartilhada a uma concepção pública de justiça para uma sociedade democrática, pois alguns valores ponderados assumidos pelos indivíduos seriam vistos como falsos (JFPnM: $395)^{23}$. Assim, o método do construtivismo político é usado para evitar o problema da verdade e a controvérsia entre realismo e antirrealismo a

\footnotetext{
${ }^{22}$ Rawls faz uma rápida análise das condições formais de ordenamento e publicidade e de como estes conceitos estão relacionados estreitamente com a teoria moral, com a intenção de apontar para as limitações de uma teoria do significado. As condições formais possuem uma força diferenciada dependendo da teoria moral a que estão associadas. Por exemplo, a condição de publicidade se harmoniza mais facilmente com algumas estruturas e concepções de pessoas que outras. De forma análoga, generalidade e universalidade possuem uma força diferenciada em uma teoria deontológica que em uma teoria teleológica. A conclusão é que as várias caracterizações destas condições estão intimamente conectadas com uma concepção moral específica da qual elas pertencem e que a determinação de seu significado não é uma base independente para o entendimento destes conceitos. Ver IMT: 295.

${ }^{23}$ JFPnM: 395: "Philosophy as the search for truth an independent metaphysical and moral order cannot, I believe, provide a workable and shared basis for a political conception of justice in a democratic society". De forma sutil, Rawls está defendendo uma concepção de filosofia não-metafísica que teria um papel de (re)construir os valores públicos assumidos socialmente, buscando identificar sua racionalidade-razoabilidade, de forma a possibilitar a estabilidade e legitimidade e não o papel de buscar uma ordem independente de valores para constituir a objetividade. É uma maneira sutil e econômica de dizer que a filosofia poderia ser vista como uma atividade de interpretação racional e não como um conhecimento absoluto sobre o real. Como defendido em SGEK, o papel da filosofia moral é organizar 0 senso moral comum do homem correto e tentar mostrar como estes juízos podem ser justificados. Ver SGEK: 52 e ODPE: 18.
} 
respeito do estatuto ontológico dos valores morais e políticos. A ideia é nem defender e nem rejeitar estas doutrinas. Parte da tradição da TCS para alcançar uma concepção praticável de objetividade e uma justificação fundada sobre o acordo em juízos reflexivos. Sua ideia básica é a de sociedade como um sistema equitativo de cooperação social, o que implica nas ideias de pessoas livres e iguais e sociedade bem-ordenada. Este é o ponto de vista social que garante a objetividade da regra. Isto aponta para uma distinção ontológica/epistemológica entre o todo e a parte, sendo que a justificação da crença se dará sempre por sua coerência com um corpo coerente de crenças e não de forma solipsista. Esta justificação possibilita uma reconciliação através da razão pública, visando alcançar uma base para a cooperação social, base esta que é a do respeito mútuo (razoabilidade e reciprocidade) e isto garante a estabilidade e legitimidade (JFPnM: 395 $)^{24}$.

\section{Considerações Finais}

A teoria moral rawlsiana apresenta uma concepção procedimental de justiça que defende a objetividade dos juízos e princípios morais de uma forma coerentista holística, rejeitando tanto o fundacionalismo quanto o ceticismo e relativismo. Este sistema coerentista de justificação resolve os principais problemas em epistemologia moral sem precisar apoiar-se em uma forte fundamentação ontológica ou mesmo epistemológica, apenas fazendo uso de uma ontologia social e uma epistemologia coerentista pressuposta. $\mathrm{O}$ regresso epistêmico é resolvido por seu holismo, uma vez que se identifica uma distinção ontológica/epistemológica entre o todo e a parte em razão do uso de uma ontologia social dada pela ideia central de sociedade como um sistema equitativo de cooperação social. Também, não se identifica nenhum dogmatismo em razão da revisibilidade dos juízos ponderados e princípios morais e da concepção não correspondentista de verdade compreendida

\footnotetext{
${ }^{24}$ Rawls ressalta que os princípios substantivos de justiça e as diretrizes de investigação da razão pública e seu princípio de legitimidade possuem a mesma base, isto é, o mesmo fundamento, que é o acordo. Isto significa que as partes na posição original, (i) ao adotar os princípios de justiça para a estrutura básica, (ii) devem também estabelecer as diretrizes e critérios da razão pública para aplicação destas normas. Ver $P L$ VI, $\S 4.4:$ 225-226. Pogge salienta que esta ideia de justificação se dá a partir da possibilidade do acordo comum, em que um apresenta sua concepção aos outros e, assim, a justificação apela para as convicções aceitas por generalidade. A justificação apela para as ideias que fazem parte da cultura política pública, propiciando uma reconstrução dos valores públicos de uma sociedade de uma forma superior que outras concepções de justiça em virtude de sua razoabilidade. Ver POGGE, 2007: 174-175.
} 
como aceitabilidade ou razoabilidade. Esta concepção não é dualista, pois pretende superar a dicotomia entre fato e valor, uma vez que a tolerância é tomada em sua acepção normativa além de descritiva. Também, não é possível perceber uma assimetria entre os termos da justificação, pois há uma reciprocidade na direção regra-caso no procedimento do equilíbrio reflexivo e uma justificação intersubjetiva, uma vez que a justificação é pública e dada por reconhecimento e não por descoberta. O problema que poderia ser apontado ao coerentismo seria o de circularidade, pois defende a tese da justificação dos princípios por sua coerência com os juízos ponderados. Entretanto, penso que a circularidade é evitada pelo argumento pragmatista de complementaridade entre justificação e legitimação, remetendo a um problema prático de garantia de estabilidade e legitimidade ao apelar para a consideração das consequências dos princípios morais no funcionamento das principais instituições sociais, políticas e econômicas.

Assim, sendo a justificação uma questão de reconciliação por razões, a justiça como equidade estabelece a coerência entre juízos e princípios morais que são acordados por sua função, estabelecendo a objetividade da norma a partir do mútuo reconhecimento. O resultado disto é a aproximação holística entre a esfera factual e normativa, uma vez que a norma moral, o justo, é visto como um fato que pode servir de razão dentro do procedimento, possibilitando uma alternativa em relação às estratégias fundacionalistas de estabelecimento de um ponto último de ancoragem aos princípios. Esta teoria não dá a última palavra a respeito do que pode ser considerado como equitativo, isto é, a respeito do conteúdo, mas aponta para a superioridade estrutural do coerentismo holístico e pragmático na filosofia moral contemporânea. Não seria este um bom ponto de partida como contraponto à intolerância crescente?

\section{REFERÊNCIAS BIBLIOGRÁFICAS}

ALSTON, William. Beyond "Justification": Dimensions of Epistemic Evaluation. Ithaca: Cornell University Press, 2005.

. "Foundationalism". In: DANCY, Jonathan; SOSA, Ernest; STEUP, Mathias (Eds.). A Companion to Epistemology. Second Edition. Oxford: Blackwell, 2010, p. 382-385. 
AUDARD, Catherine. John Rawls. Oxford: McGill-Quen's University Press, 2007.

AUDI, Robert. The Structure of Justification. Cambridge: Cambridge University Press, 1993.

"Foundationalism, Coherentism, and Epistemological Dogmatism”. Philosophical Perspectives, Vol. 2, Epistemology, 1988: 407-442.

Epistemology: A Contemporary Introduction to the Theory of Knowledge. Second Edition. London: Routledge, 2003.

BARRY, Brian. The Liberal Theory of Justice: A Critical Examination of the Principal Doctrines in "A Theory of Justice" by John Rawls. Oxford: Oxford University Press, 1973.

BONJOUR, Laurence. The Structure of Empirical Knowledge. Cambridge: Harvard University Press, 1985.

"A Version of Internalist Foundationalism". In: BONJOUR, L.;

SOSA, E. Epistemic Justification: Internalism Vs. Externalism, Foundationalism Vs. Virtues. Oxford: Blackwell, 2008, p. 3-96.

Epistemology: Classical Problems and Contemporary Responses.

Second Edition. Lanham: Rowman \& Littlefield, 2010.

BRANDT, Richard. A Theory of the Good and the Right. New York: Prometheus Books, 1998 (1979).

BRINK, David. Moral Realism and the Foundations of Ethics. Cambridge: Cambridge University Press, 1989.

DANCY, Jonathan. Introduction to Contemporary Epistemology. Oxford: Blackwell, 2010a.

."Moral Epistemology". In: DANCY, Jonathan; SOSA, Ernest; STEUP, Mathias (Eds.). A Companion to Epistemology. Second Edition. Oxford: Blackwell, 2010b, p. 532-537.

DANIELS, Norman. "Wide Reflective Equilibrium and Theory Acceptance in Ethics”. Journal of Philosophy, Vol. 76, No. 5, 1979: 256-282.

. Justice and Justification: Reflective Equilibrium in Theory and Practice. Cambridge: Cambridge University Press, 1996. 
DePAUL, Michael R. "Two Conceptions of Coherence Methods in Ethics". Mind, New Series, Vol. 96, No. 384, 1987: 463-481.

ESFELD, Michael. "Holism and Analytic Philosophy". Mind, New Series, Vol. 107, No. 426, 1998: 365-380.

FEINBERG, Joel. "Rawls and Intuitionism". In: DANIELS, Norman (Ed.). Reading Rawls: Critical Studies on Rawls ' 'A Theory of Justice '. Stanford, California: Stanford University Press, 1975, p. 108-124.

FREEMAN, Samuel. Rawls. London: Routledge, 2007a.

Justice and the Social Contract: Essays on Rawlsian Political Philosophy. New York: Oxford University Press, 2007b.

GRAHAM, Paul. Rawls. Oxford: Oneworld, 2007.

HARE, R. M. "Rawls` Theory of Justice”. In: DANIELS, Norman (Ed.). Reading Rawls: Critical Studies on Rawls ' 'A Theory of Justice '. Stanford, California: Stanford University Press, 1975, p. 81-107.

HEDRICK, Todd. Rawls and Habermas: Reason, Pluralism, and the Claims of Political Philosophy. Stanford, California: Stanford University Press, 2010.

HUEMER, Michael. "Foundations and Coherence". In: DANCY, Jonathan; SOSA, Ernest; STEUP, Mathias (Eds.). A Companion to Epistemology. Second Edition. Oxford: Blackwell, 2010, p. 22-33.

JAMIESON, Dale. "The Method and Moral Theory". In: SINGER, Peter. $A$ Companion to Ethics. Oxford: Blackwell, 2000, p. 476-490.

LEHNING, Percy. John Rawls: An Introduction. New York: Cambridge University Press, 2009.

LEHRER, Keith. "Coherentism". In: DANCY, Jonathan; SOSA, Ernest; STEUP, Mathias (Eds.). A Companion to Epistemology. Second Edition. Oxford: Blackwell, 2010, p. 278-281.

LYONS, David. "Nature and Soundness of the Contract and Coherence Arguments”. In: DANIELS, Norman (Ed.). Reading Rawls: Critical Studies on Rawls' 'A Theory of Justice '. Stanford, California: Stanford University Press, 1975, p. 141-167. 
PETTIT, Philip. "Rawls`s Political Ontology". Politics, Philosophy \& Economics, 4 (2), 2005: 157-174.

POGGE, Thomas W. "On Justification”. In: John Rawls: His Life and Theory of Justice. Oxford: Oxford University Press, 2007, p. 161-177.

QUINE, W.V. Word and Object. Cambridge, Mass.: MIT Press, 1960.

. Ontological Relativity and Other Essays. New York: Columbia University Press, 1969.

RAZ, Joseph. "Facing Diversity: The Case of Epistemic Abstinence". Philosophy and Public Affairs, Vol. 19, No. 1, 1990: 3-46.

RAWLS, John. A Theory of Justice. Original Edition. Cambridge, Mass.: Harvard University Press, 1971.

. A Theory of Justice. Revised Edition. Cambridge, Mass.: Harvard University Press, 1999.

. Political Liberalism. New York: Columbia University Press, 1996.

. The Law of Peoples. Cambridge, Mass.: Harvard University Press, 2001.

. Collected Papers (CP). Ed. S. Freeman. Cambridge, Mass.: Harvard University Press, 1999.

. Justice as Fairness: A Restatement. Ed. E. Kelly. Cambridge, Mass.: Harvard University Press, 2001.

A Study on the Grounds of Ethical Knowledge: Considered with Reference to Judgments on the Moral Worth of Character. PhD. Dissertation. Princeton University, 1950.

. "Outline of a Decision Procedure for Ethics" (1951). In CP. 1-19.

. "The Independence of Moral Theory” (1975). In: CP. 286-302.

. "Justice as Fairness: Political not Metaphysical” (1985). In: CP. 388-

414.

ROBINSON, Luke. "Moral Holism, Moral Generalism, and Moral Dispositionalism”. Mind, Vol. 115, No. 458, 2006: 331-360. 
SAYRE-McCORD, Geofrey. "Coherentism and the Justification of Moral Beliefs”. In: TIMMONS, Mark; SINNOTT-ARMSTRONG, Walter (Eds.). Moral Knowledge? Oxford: Oxford University Press, 1996, p. 137-189.

Reimpresso em SHAFER-LANDAU, Russ (Ed.). Ethical Theory: An Anthology. Oxford: Blackwell, 2007, p. 123-139.

SCANLON, T. M. "Rawls on Justification". In: S. FREEMAN (Ed.). The Cambridge Companion to Rawls. Cambridge: Cambridge University Press, 2003, p. 139-167.

SIDGWICK, Henry. The Methods of Ethics. Seventh Edition. Indianapolis: Hackett, 1981.

SINGER, Peter. "Sidgwick and Reflective Equilibrium". Monist, LVIII, 3, 1974: 490-517. Reimpresso em SINGER, Peter. Unsanctifying Human Life. Edited by Helga Kuhse. Oxford: Blackwell, 2022, p. 27-50.

SMITH, Michael. The Moral Problem. Oxford: Blackwell, 1994.

SOSA, Ernest. Knowledge in Perspective: Selected Essays in Epistemology. Cambridge: Cambridge University Press, 1995.

SOSA, Ernest; KIM, Jaegwon (Eds.). Epistemology: An Anthology. Oxford: Blackwell, 2005.

WEBER, Eric Thomas. Rawls, Dewey and Constructivism: On the Epistemology of Justice. London: Continuum, 2010.

WILLIAMS, Bernard. "Internal and External Reasons". In: HARRISON, Ross (Ed.). Rational Action. Cambridge: Cambridge University Press, 1979, p. 1728. Reimpresso em SHAFER-LANDAU, R.; CUNEO, T. (Eds.). Foundations of Ethics: An Anthology. Oxford: Blackwell, 2008, p. 292-298. 